\title{
PRIMER REGISTRO DE PSECTRASCELIS SULCICOLLIS (WATERHOUSE 1841) PARA CHILE (COLEOPTERA: TENEBRIONIDAE) Y PRIMER REGISTRO DEL GÉNERO PARA LA REGION DE MAGALLANES
}

\author{
FIRST RECORD OF PSECTRASCELIS SULCICOLLIS (WATERHOUSE \\ 1841) (COLEOPTERA: TENEBRIONIDAE) TO CHILE AND THE FIRST \\ RECORD OF THE GENUS FOR THE REGION OF MAGALLANES
}

Álvaro Zúñiga- Reinoso ${ }^{1} \&$ Gustavo E. Flores ${ }^{2}$

El género Psectrascelis Solier pertenece a la tribu Nycteliini, una tribu de Pimeliinae endémica del cono Sur de Sudamérica (Flores, 1997). Con 81 especies aceptadas en la actualidad (revisar Peña 1985, Flores 2007, Vidal \& Guerrero, 2007), es el género más diverso de la tribu en cuanto a número de especies (Flores, 1997). Estos insectos son especies ápteras, de hábitos nocturnos que habitan particularmente sistemas áridos y semiáridos del sur de Perú y Bolivia hasta el sur de Chile y Argentina (Peña, 1985), tanto en desiertos costeros e interiores, estepas y la altamontaña (Flores, 1997). Son especialmente abundantes tanto en el desierto costero de Chile, como en el altiplano y la estepa argentina, pudiendo encontrarse más de dos especies congenéricas en simpatría (Peña, 1985). Hacia el sur el número de especies disminuye considerablemente y en la Patagonia Austral se han registrado sólo cinco especies (Peña, 1985).
El límite austral del género es el río Santa Cruz, Argentina, que según Peña (1985) es una barrera infranqueable para sus especies. Por lo tanto, el objetivo de este trabajo es dar a conocer el primer registro de Psectrascelis sulcicollis (Waterhouse, 1841) para Chile y el primer registro del género Psectrascelis al sur del río Santa Cruz, en la región de Magallanes.

Material examinado ${ }^{1}$ : CHILE. Magallanes, Última Esperanza. Sierra Baguales: Estancia Sierra Leona. 21-XII-2010. 2 ejemplares (1 IADIZA, 1 MNNC). Leg. A. Zúñiga. Georeferencia: 5053'16.30”S- 72²1'21.70”O.

\section{COMENTARIOS}

A pesar de ser coleópteros conspicuos en

${ }^{1}$ Los ejemplares fueron encontrados muertos, con algunas de sus extremidades mutiladas por lo que el material fue comparado con material depositado en la colección de IADIZA

\footnotetext{
${ }^{1}$ Programa de Doctorado en Ecología y Biología Evolutiva, Departamento de Ciencias Ecológicas, Facultad de Ciencias, Universidad de Chile. Santiago, Chile. alzure@gmail.com

${ }^{2}$ CONICET, Laboratorio de Entomología, Instituto Argentino de Investigaciones de las Zonas Áridas (IADIZA, CCT CONICET Mendoza), Casilla de correo 507, 5500 Mendoza, Argentina.
} 
tamaño y forma, Psectracselis sigue siendo un grupo taxonómicamente confuso, con especies dudosas y muchas especies con rangos de distribución poco claros, como es el caso de este hallazgo. La especie que acá se registra corresponde a Psectrascelis sulcicollis. Esta especie ha sido citada sólo para Argentina (Blackwelder, 1957), en la provincia de Santa Cruz, sin una localidad precisa (Waterhouse, 1841), pero Peña (1985), en base a un ejemplar (i.e Holotipo) colectado por C. Darwin y rotulado: St. Cruz, la situó arbitrariamente en la costa atlántica. El ejemplar holotipo de su sinónimo posterior, Psectrascelis abnormis (Burmeister, 1875) fue colectado en la margen norte de la desembocadura del río Santa Cruz (Burmeister, 1875). Con este nuevo registro se amplía el rango de distribución del género Psectrascelis, y lo ubica al sur del río Santa Cruz. Por lo tanto, P. sulcicollis es la especie mas austral del género y habita ambos lados de dicho río, siendo además, el primer registro de $P$. sulcicollis en Chile. Biogeográficamente, el río Santa Cruz no constituye una barrera geográfica para la distribución del género Psectrascelis como lo propuesto por Peña (1985), además la localidad en las que se registra $P$. sulcicollis, forma parte de la estepa patagónica incluida dentro de las áreas más secas de la región de Magallanes y con una fuerte influencia de la estepa argentina (Pisano, 1977). Estos resultados son coincidentes con otros hallazgos reportados para el género Nyctelia Latreille (Tenebrionidae: Nycteliini) por Zúñiga-Reinoso \& Jerez (2012). En este sentido, el sector de Sierra Baguales podría constituir una zona ecotonal, donde se pueden encontrar componentes de los distritos biogeográficos Patagonia Central y Fueguino propuesto por (Morrone et al., 2002). Estas zonas de transición pueden ser de gran interés para estudios de tipo biogeográficos y/o de conservación, ya que presenta una alta diversidad de coleópteros debido al aporte de fauna de dos distritos biogeográficos.

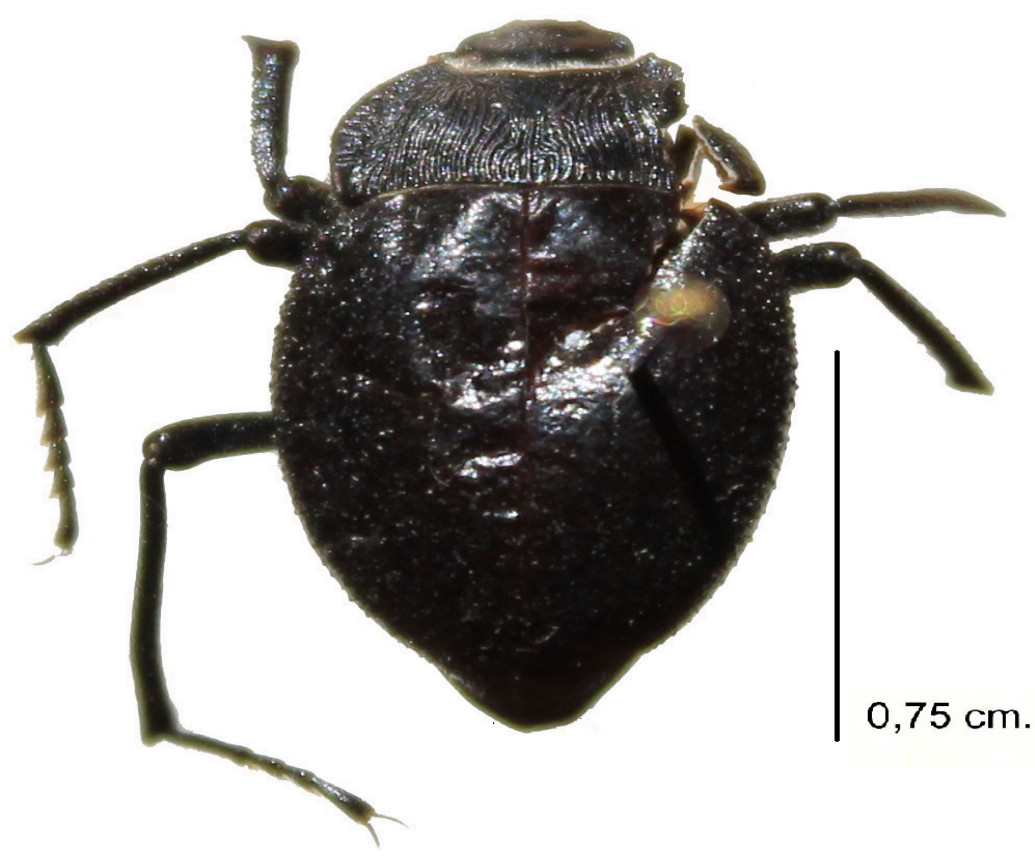

Fig. 1. Ejemplar macho de Psectrascelis sulcicollis encontrado en la localidad de Estancia Sierra Leona, en la Región de Magallanes. 


\section{AGRADECIMIENTOS}

El primer autor agradece a la beca CONICYT No 21110367 para estudios de doctorado nacionales.

\section{LITERATURA CITADA}

Blackwelder, R.E. (1957). Checklist of the coleopterous insects of Mexico, Central America, The West Indies, and South America. Bulletin of the United States National Museum, 185, 927-1492.

Burmeister, H. (1875) Melanosoma Argentina. Stettiner Entomologische Zeitung, 36, 457-500.

Flores, G.E. (1997). Revisión de la tribu Nycteliini (Coleoptera: tenebrionidae). Revista de la Sociedad entomológica Argentina,. 56, 1-19.

Flores, G.E. (2007). Two new species of Psectrascelis (Coleoptera: Tenebrionidae) from Western Argentina. Revista de la Sociedad Entomológica Argentina, 66, 91-97.

Morrone, J.J., S. Roig-Juñent \& G.E. Flores (2002). Delimitation of biogeographic districts in central Patagonia (southern South America), based on beetle distributional patterns (Coleoptera: Carabidae and Tenebrionidae). Revista del Museo Argentino de Ciencias Naturales, 4, 1-6.
Peña, L.E. (1985). Revisión del género Psectrascelis Solier (Coleoptera: Tenebrionidae). Revista Chilena de Entomología, 12, 15-51.

Pisano, E. (1977). Fitogeografía de Fuego-Patagonia chilena: I- Comunidades vegetales entre las latitudes $52^{\circ}$ y $56^{\circ} \mathrm{S}$. Anales del Instituto de la Patagonia, 8, 121-246.

Waterhouse, G.R. (1841). Description of numerous species of coleopterous insects from the southern parts of South America. Proceedings of the Zoological Society of London, 9, 105-128.

Smith, K.G.V. (1987). Darwin's Insects. Charles Darwin's Entomological Notes. Bulletin of the British Museum (Natural History). Historical Series, 14, 1-143.

Vidal, P. \& M. Guerrero (2007). Nuevas especies de Psectrascelis Solier, 1836 (Coleoptera: Tenebrionidae) de Chile. En Vidal, P. \& M. Guerrero. 2007 (eds.), Los Tenebrionidos de Chile, Ediciones Universidad Católica de Chile, Santiago, Chile.

Zúñiga-Reinoso, A. \& V. Jerez (2012). Sobre la presencia de Nyctelia fitzroyi Waterhouse, 1841 y Nyctelia solieri Waterhouse, 1841 (Coleoptera: Tenebrionidae) en la región de Magallanes. Anales Instituto Patagonia, 40, 115-118. 
